\title{
Molecular Structure and Vibrational Analysis of 1-Bromo-2-Chlorobenzene Using ab initio HF and Density Functional Theory (B3LYP) Calculations
}

\author{
G. Shakila, ${ }^{1}$ S. Periandy, ${ }^{2}$ and S. Ramalingam ${ }^{3}$ \\ ${ }^{1}$ Department of Physics, Bharathidasan Government College for Women, Puducherry 605003, India \\ ${ }^{2}$ Department of Physics, Tagore Arts College, Puducherry 605008, India \\ ${ }^{3}$ Department of Physics, A.V.C. College, Mayiladuthurai, Tamilnadu 609305, India
}

Correspondence should be addressed to S. Ramalingam, ramalingam.physics@gmail.com

Received 21 February 2011; Accepted 16 June 2011

Academic Editor: Amlan K. Roy

Copyright ( $) 2011$ G. Shakila et al. This is an open access article distributed under the Creative Commons Attribution License, which permits unrestricted use, distribution, and reproduction in any medium, provided the original work is properly cited.

\begin{abstract}
The FT-Raman and FT-IR spectra for 1-bromo-2-chlorobenzene (1B2CB) have been recorded in the region $4000-100 \mathrm{~cm}^{-1}$ and compared with the harmonic vibrational frequencies calculated using HF/DFT (B3LYP) method by employing 6-31+G (d, p) and $6-311++\mathrm{G}(\mathrm{d}, \mathrm{p})$ basis set with appropriate scale factors. IR intensities and Raman activities are also calculated by HF and DFT (B3LYP) methods. Optimized geometries of the molecule have been interpreted and compared with the reported experimental values of some substituted benzene. The experimental geometrical parameters show satisfactory agreement with the theoretical prediction from HF and DFT. The scaled vibrational frequencies at B3LYP/6-311++G (d, p) seem to coincide with the experimentally observed values with acceptable deviations. The theoretical spectrograms (IR and Raman) have been constructed and compared with the experimental FT-IR and FT-Raman spectra. Some of the vibrational frequencies of the benzene are affected upon profusely with the halogen substitutions in comparison to benzene, and these differences are interpreted.
\end{abstract}

\section{Introduction}

Aromatic compounds such as benzene derivative compounds are commonly used for chronic inflammation treatment products in pharmaceutical products. Benzene is frequently used as an industrial solvent, especially for degreasing metal. Chlorobenzene is an important industrial solvent and a widely used intermediate in production of commodities such as herbicides, dyestuffs, and rubber [1]. The major use of Chlorobenzene is as an intermediate in the production of commodities such as herbicides, dyestuffs, and rubber. Chlorobenzene is also used as a high-boiling solvent in many industrial applications as well as in the laboratory. Bromobenzene can be used to prepare the corresponding Grignard reagent, phenyl magnesium bromide [2]. The combined Chlorobromobenzene is also used for the manufacture of some biological and industrial solvents. In recent years, chlorobromobenzene has been the frequent subject of experimental and theoretical work because of its significance in industry and environment. Literature survey reveals that to the best of our knowledge no ab initio HF/DFT with $6-31+\mathrm{G}(\mathrm{d}, \mathrm{p})$ and $6-311++\mathrm{G}(\mathrm{d}, \mathrm{p})$ basis sets calculations of $1-\mathrm{Br}-2-\mathrm{CB}$ have been reported so far. It is, therefore thought worthwhile to make a comprehensive vibrational analysis using both experimentally observed IR and Raman wavenumbers and theoretically calculated vibrational spectra.

In this study, molecular geometry, optimized parameters, and vibrational frequencies are computed and the performance of the computational methods for ab initio (HF), hybrid density functional methods B3LYP at 6-31G+ $(d, p)$ and 6-311G++ (d, p) basis sets are compared. These methods predict relatively accurate molecular structure and vibrational spectra with moderate computational effort. In particular, for polyatomic molecules the DFT methods lead to the prediction of more accurate molecular structure and vibrational frequencies than the conventional ab initio Hartree-Fock calculations. In DFT methods, Becke's three parameter exact exchange-functional (B3) [3] combined with gradient-corrected correlational functional of Lee et al. 


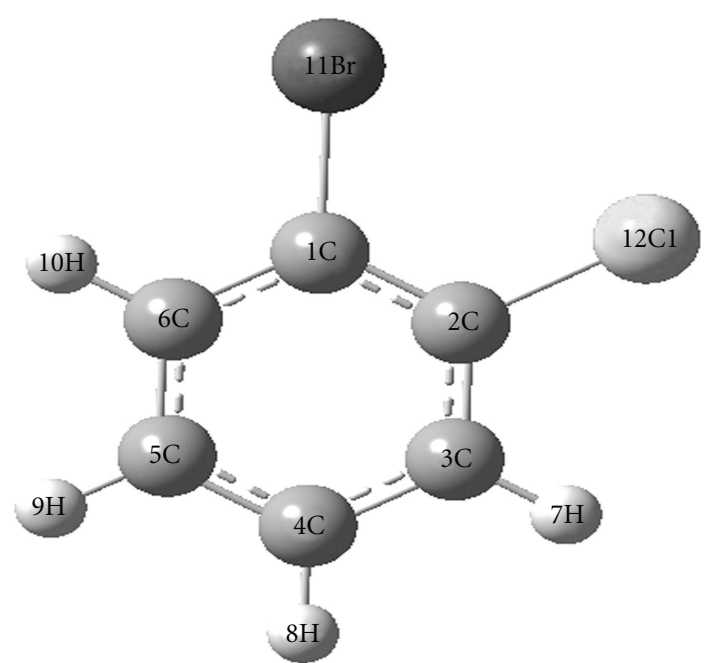

Figure 1: Molecular structure of 1-bromo-2-chlorobenzene.

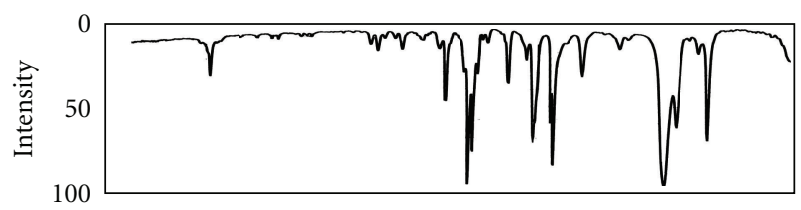

(a)

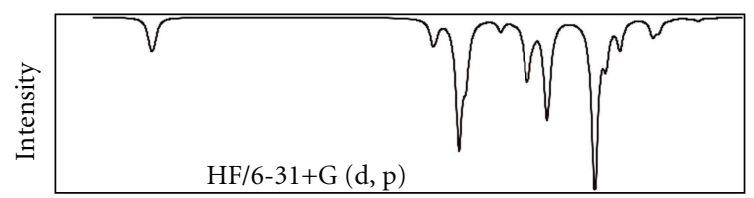

(b)

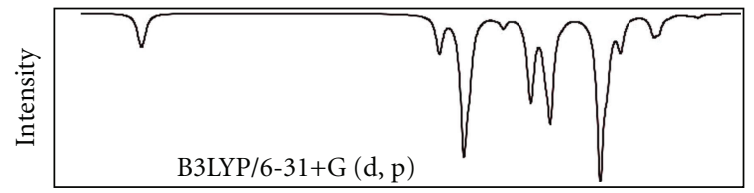

(c)

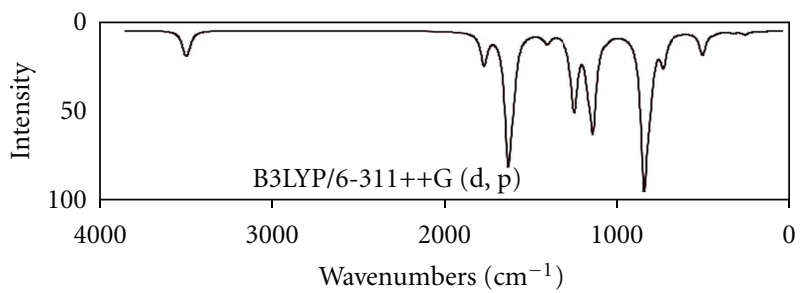

(d)

Figure 2: Experimental (a), calculated (b), (c) and (d) FT-IR spectra of 1-bromo-2-chlorobenzene.

(LYP) $[4,5]$ are the best predicting results for molecular geometry and vibrational wave numbers for moderately larger molecule [6-8].

\section{Experimental Details}

The spectroscopic grade 1-Br-2-CB was purchased from Sigma Aldrich chemicals, USA, and used as such for

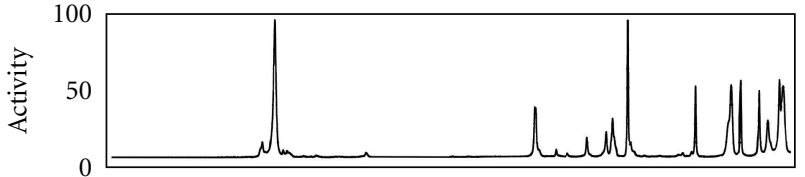

(a)

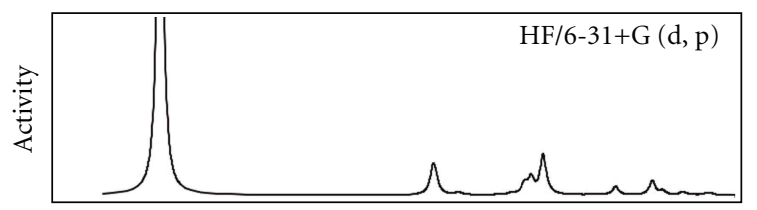

(b)

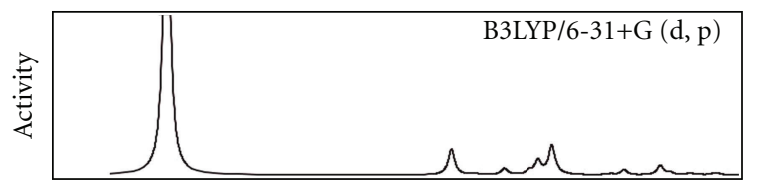

(c)

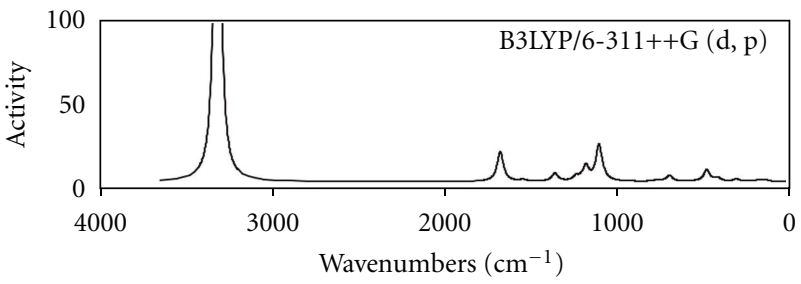

(d)

FIgURE 3: Experimental (a), calculated (b), (c) and (d) FT-Raman spectra of toluic acid.

recording spectra without further purification. The FT-IR spectrum of the 1-Br-4-CB was recorded in Bruker IFS $66 \mathrm{~V}$ spectrometer in the range of 4000 to $100 \mathrm{~cm}^{-1}$. The spectral resolution is $\pm 2 \mathrm{~cm}^{-1}$. The FT-Raman spectrum of 1-Br-2-CB was also recorded in the same instrument with FRA 106 Raman module equipped with Nd: YAG laser source operating at $1.064 \mu \mathrm{m}$ with $200 \mathrm{Mw}$ power. Both the spectra were recorded in the range of 4000 to $100 \mathrm{~cm}^{-1}$ with scanning speed of $30 \mathrm{~cm}^{-1} \mathrm{~min}^{-1}$ of spectral width $2 \mathrm{~cm}^{-1}$. The frequencies of all sharp bands are accurate to $\pm 1 \mathrm{~cm}^{-1}$.

\section{Computational Methods}

HF/DFT calculations for 1-bromo-2-chlorobenzene are performed using GAUSSIAN $03 \mathrm{~W}$ program package on Pentium IV processor personal computer without any constraint on the geometry. The molecular structure of the title compound in the ground state is computed both ab initio HF with 6-311G (d, p) and DFT (B3LYP) with 6-311++G (d, p) and $6-31+G(d, p)$ basis sets. The comparative IR and Raman spectra of experimental and calculated (HF/B3LYP) are given in Figures 2 and 3, respectively. The optimized structural parameters are used in the vibrational frequency calculations at HF and DFT levels. The minimum energy of geometrical structure is obtained by using same basis sets of HF and DFT methods those which are previously mentioned. All the computations have been done by adding polarization function $\mathrm{d}$ and diffuse function on heavy atoms and 


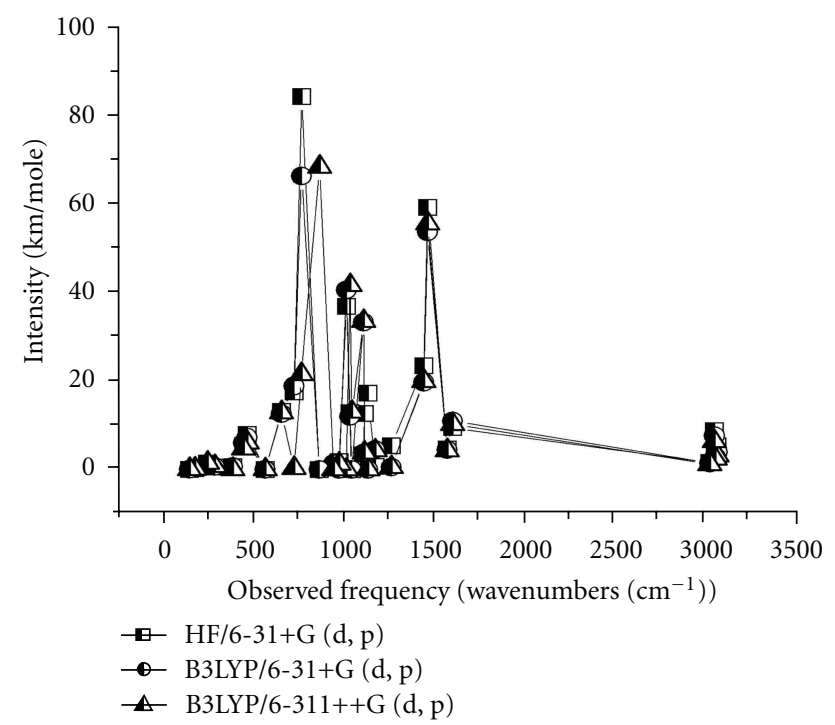

Figure 4: Comparative graph of IR Intensities by HF and DFT (B3LYP).

polarization function $\mathrm{p}$ and diffuse function on hydrogen atoms, in addition to triple split valence basis set (6-311G $(d, p)$ ), for better treatment of polar bonds. The calculated frequencies are scaled by 0.902 and 0.884 for $\mathrm{HF} / 6-311+\mathrm{G}$ $(\mathrm{d}, \mathrm{p})[9,10]$. For B3LYP/6-31G+ $(\mathrm{d}, \mathrm{p})$ is scaled by 0.923 , $0.977,0.872$, and 0.945 and for B3LYP/6-311++G (d, p) basis set, calculated frequency is scaled with $0.927,0.976,0.987$, 0.885 , and 1.008 [11]. HF/DFT calculations for $1-\mathrm{Br}-2-\mathrm{CB}$ are performed using GAUSSIAN $03 \mathrm{~W}$ program package on Pentium IV processor personal computer without any constraint on the geometry $[12,13]$. The comparative values of IR intensities and Raman activities are presented in Table 3 and their corresponding graphs are given in Figures 4 and 5 , respectively.

\section{Results and Discussion}

4.1. Molecular Geometry. The molecular structure of the 1-Br-2-CB belongs to $\mathrm{C}_{S}$ point group symmetry. The optimized molecular structure of title molecule is obtained from GAUSSAN $03 \mathrm{~W}$, and GAUSSVIEW programs are shown in Figure 1. The molecule contains $\mathrm{Cl}$ and $\mathrm{Br}$ connected with benzene ring. The structure optimization zero point vibrational energy of the title compound in $\mathrm{HF} / 6-31+\mathrm{G}(\mathrm{d}, \mathrm{p})$, B3LYP/6-31+G (d, p), and B3LYP/6-311++G (d, p) are $-226013.3,-215997.0$, and -211074.9 joules/Mol, respectively. The comparative optimized structural parameters such as bond lengths, bond angles, and dihedral angles are presented in Table 1. The comparative graphs of bond lengths, bond angles, and dihedral angles of 1-Br-2-CB for four sets are presented in Figures 6, 7, and 8, respectively.

From theoretical values, it is found that most of the optimized bond lengths are slightly larger than the experimental values, because the theoretical calculations belong to isolated molecules in gaseous phase and the experimental results belong to molecules in solid state. Comparing bond angles and lengths of B3LYP with those of HF, as a whole the

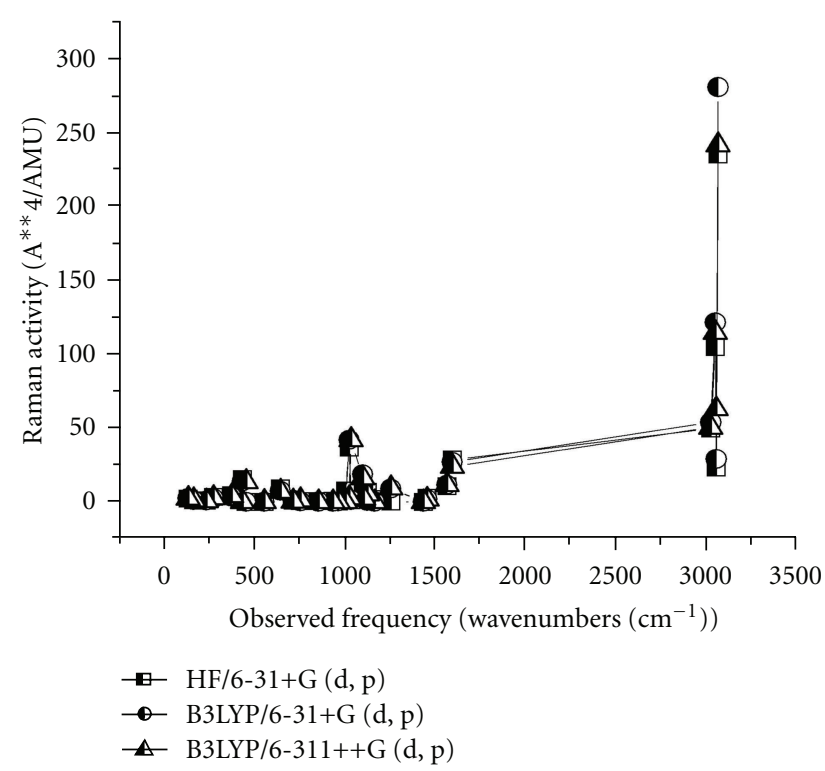

FIGURE 5: Comparative graph of Raman intensities by HF and DFT (B3LYP).

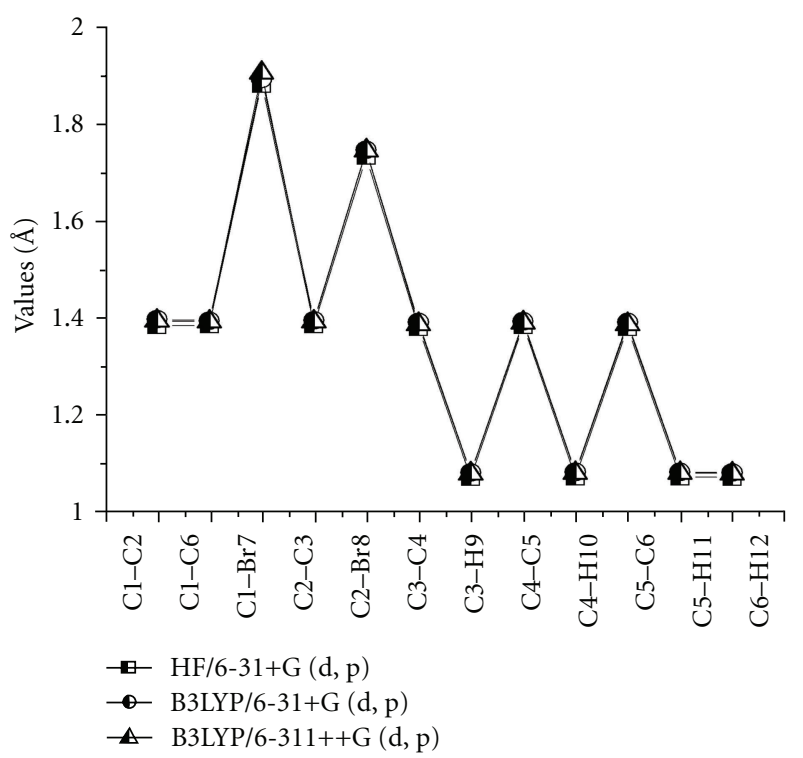

Figure 6: Bond length differences between theoretical approach (HF and DFT).

formers are bigger than the laters and the B3LYP calculated values correlate well compared with the experimental data. Despite the differences, calculated geometrical parameters represent a good approximation, and they are the bases for the calculating other parameters, such as vibrational frequencies and thermodynamics properties.

The benzene ring appears little distorted and angles slightly out of perfect hexagonal structure. It is due to the substitutions of the bromine and chlorine atom in the place of $\mathrm{H}$ atoms. According to the calculated values (B3LYP/6-311++G $(d, p)$ ), the order of the optimized bond lengths of the six $\mathrm{C}-\mathrm{C}$ bonds of the ring as $\mathrm{C}_{3}-\mathrm{C}_{4}=\mathrm{C}_{5}-$ $\mathrm{C}_{6}<\mathrm{C}_{4}-\mathrm{C}_{5}<\mathrm{C}_{1}-\mathrm{C}_{6}=\mathrm{C}_{2}-\mathrm{C}_{3}<\mathrm{C}_{1}-\mathrm{C}_{2}$. From the order, 
TABLE 1: Optimized geometrical parameters for 1-bromo-2-chlorobenzene computed at HF/6-31+G (d, p), B3LYP/6-31+G (d, p), and B3LYP/6-31G++ $(\mathrm{d}, \mathrm{p})$ basis sets.

\begin{tabular}{|c|c|c|c|c|}
\hline \multirow{2}{*}{ Geometrical Parameters } & \multicolumn{4}{|c|}{ Methods } \\
\hline & $\mathrm{HF} / 6-31+\mathrm{G}(\mathrm{d}, \mathrm{p})$ & B3LYP/6-31+G $(d, p)$ & B3LYP/6-311++G $(d, p)$ & Experimental value \\
\hline \multicolumn{5}{|l|}{ Bond length $(\AA)$} \\
\hline $\mathrm{C}_{1}-\mathrm{C}_{2}$ & 1.3865 & 1.400 & 1.397 & - \\
\hline $\mathrm{C}_{1}-\mathrm{C}_{6}$ & 1.388 & 1.397 & 1.395 & - \\
\hline $\mathrm{C}_{1}-\mathrm{Br}_{11}$ & 1.8837 & 1.895 & 1.908 & 1.867 \\
\hline $\mathrm{C}_{2}-\mathrm{C}_{3}$ & 1.388 & 1.398 & 1.395 & - \\
\hline $\mathrm{C}_{2}-\mathrm{Cl}_{12}$ & 1.7355 & 1.749 & 1.748 & 1.745 \\
\hline $\mathrm{C}_{3}-\mathrm{C}_{4}$ & 1.3824 & 1.394 & 1.390 & - \\
\hline $\mathrm{C}_{3}-\mathrm{H}_{7}$ & 1.0735 & 1.084 & 1.082 & 1.080 \\
\hline $\mathrm{C}_{4}-\mathrm{C}_{5}$ & 1.3868 & 1.396 & 1.393 & - \\
\hline $\mathrm{C}_{4}-\mathrm{H}_{8}$ & 1.0748 & 1.085 & 1.083 & 1.080 \\
\hline $\mathrm{C}_{5}-\mathrm{C}_{6}$ & 1.3828 & 1.394 & 1.390 & - \\
\hline $\mathrm{C}_{5}-\mathrm{H}_{9}$ & 1.0747 & 1.085 & 1.083 & 1.080 \\
\hline $\mathrm{C}_{6}-\mathrm{H}_{10}$ & 1.0735 & 1.084 & 1.082 & 1.080 \\
\hline \multicolumn{5}{|l|}{ Bond angle $\left({ }^{\circ}\right)$} \\
\hline $\mathrm{C}_{2}-\mathrm{C}_{1}-\mathrm{C}_{6}$ & 119.3229 & 119.25 & 119.79 & - \\
\hline $\mathrm{C}_{2}-\mathrm{C}_{1}-\mathrm{Br}_{11}$ & 122.2402 & 121.88 & 121.87 & 114.4 \\
\hline $\mathrm{C}_{6}-\mathrm{C}_{1}-\mathrm{Br}_{11}$ & 118.4369 & 118.85 & 118.32 & - \\
\hline $\mathrm{C}_{1}-\mathrm{C}_{2}-\mathrm{C}_{3}$ & 120.2134 & 120.28 & 119.73 & - \\
\hline $\mathrm{C}_{1}-\mathrm{C}_{2}-\mathrm{Cl}_{12}$ & 121.8473 & 121.44 & 121.86 & 116.3 \\
\hline $\mathrm{C}_{3}-\mathrm{C}_{2}-\mathrm{Cl}_{12}$ & 117.9394 & 118.26 & 118.40 & 116.3 \\
\hline $\mathrm{C}_{2}-\mathrm{C}_{3}-\mathrm{C}_{4}$ & 120.1128 & 120.01 & 120.26 & - \\
\hline $\mathrm{C}_{2}-\mathrm{C}_{3}-\mathrm{H}_{7}$ & 119.1113 & 119.08 & 118.83 & - \\
\hline $\mathrm{C}_{4}-\mathrm{C}_{3}-\mathrm{H}_{7}$ & 120.7759 & 120.90 & 120.89 & - \\
\hline $\mathrm{C}_{3}-\mathrm{C}_{4}-\mathrm{C}_{5}$ & 119.9138 & 119.96 & 119.98 & - \\
\hline $\mathrm{C}_{3}-\mathrm{C}_{4}-\mathrm{H}_{8}$ & 119.6402 & 119.56 & 119.51 & - \\
\hline $\mathrm{C}_{5}-\mathrm{C}_{4}-\mathrm{H}_{8}$ & 120.4459 & 120.46 & 120.49 & - \\
\hline $\mathrm{C}_{4}-\mathrm{C}_{5}-\mathrm{C}_{6}$ & 119.8645 & 119.92 & 119.98 & - \\
\hline $\mathrm{C}_{4}-\mathrm{C}_{5}-\mathrm{H}_{9}$ & 120.5147 & 120.54 & 120.52 & - \\
\hline $\mathrm{C}_{6}-\mathrm{C}_{5}-\mathrm{H}_{9}$ & 119.6208 & 119.53 & 119.48 & - \\
\hline $\mathrm{C}_{1}-\mathrm{C}_{6}-\mathrm{C}_{5}$ & 120.5726 & 120.56 & 120.23 & - \\
\hline $\mathrm{C}_{1}-\mathrm{C}_{6}-\mathrm{H}_{10}$ & 119.185 & 119.07 & 119.16 & - \\
\hline $\mathrm{C}_{5}-\mathrm{C}_{6}-\mathrm{H}_{10}$ & 120.2424 & 120.35 & 120.60 & - \\
\hline \multicolumn{5}{|l|}{ Dihedral angle $\left(^{\circ}\right)$} \\
\hline $\mathrm{C}_{6}-\mathrm{C}_{1}-\mathrm{C}_{2}-\mathrm{C}_{3}$ & 0.0 & 0.0 & 0.0 & - \\
\hline $\mathrm{C}_{6}-\mathrm{C}_{1}-\mathrm{C}_{2}-\mathrm{Br}_{11}$ & 180.0 & 180.0 & 180.0 & - \\
\hline $\mathrm{Br}_{11}-\mathrm{C}_{1}-\mathrm{C}_{2}-\mathrm{C}_{3}$ & 180.0 & 180.0 & 180.0 & - \\
\hline $\mathrm{Br}_{11}-\mathrm{C}_{1}-\mathrm{C}_{2}-\mathrm{Br}_{11}$ & 0.0 & 0.0 & 0.0 & - \\
\hline $\mathrm{C}_{2}-\mathrm{C}_{1}-\mathrm{C}_{6}-\mathrm{C}_{5}$ & 0.0 & 0.0 & 0.0 & - \\
\hline $\mathrm{C}_{2}-\mathrm{C}_{1}-\mathrm{C}_{6}-\mathrm{H}_{10}$ & 180.0 & 180.0 & 180.0 & - \\
\hline $\mathrm{Br}_{11}-\mathrm{C}_{1}-\mathrm{C}_{6}-\mathrm{C}_{5}$ & 180.0 & 180.0 & 180.0 & - \\
\hline $\mathrm{Br}_{11}-\mathrm{C}_{1}-\mathrm{C}_{6}-\mathrm{H}_{10}$ & 0.0 & 0.0 & 0.0 & - \\
\hline $\mathrm{C}_{1}-\mathrm{C}_{2}-\mathrm{C}_{3}-\mathrm{C}_{4}$ & 0.0 & 0.0 & 0.0 & - \\
\hline $\mathrm{C}_{1}-\mathrm{C}_{2}-\mathrm{C}_{3}-\mathrm{H}_{7}$ & 180.0 & 180.0 & 180.0 & - \\
\hline $\mathrm{Cl}_{12}-\mathrm{C}_{2}-\mathrm{C}_{3}-\mathrm{C}_{4}$ & 180.0 & 180.0 & 180.0 & - \\
\hline $\mathrm{Cl}_{12}-\mathrm{C}_{2}-\mathrm{C}_{3}-\mathrm{H}_{7}$ & 0.0 & 0.0 & 0.0 & - \\
\hline
\end{tabular}


TABle 1: Continued.

\begin{tabular}{lcccc}
\hline Geometrical Parameters & & \multicolumn{3}{c}{ Methods } \\
HF/6-31+G $(\mathrm{d}, \mathrm{p})$ & B3LYP/6-31+G $(\mathrm{d}, \mathrm{p})$ & $\mathrm{B}$ LYP/6-311++G $(\mathrm{d}, \mathrm{p})$ & Experimental value \\
\hline $\mathrm{C}_{2}-\mathrm{C}_{3}-\mathrm{C}_{4}-\mathrm{C}_{5}$ & 0.0 & 0.0 & 0.0 & - \\
$\mathrm{C}_{2}-\mathrm{C}_{3}-\mathrm{C}_{4}-\mathrm{H}_{8}$ & 180.0 & 180.0 & 180.0 & - \\
$\mathrm{H}_{7}-\mathrm{C}_{3}-\mathrm{C}_{4}-\mathrm{C}_{5}$ & 180.0 & 180.0 & 180.0 & - \\
$\mathrm{H}_{7}-\mathrm{C}_{3}-\mathrm{C}_{4}-\mathrm{H}_{8}$ & 0.0 & 0.0 & 0.0 & - \\
$\mathrm{C}_{3}-\mathrm{C}_{4}-\mathrm{C}_{5}-\mathrm{C}_{6}$ & 0.0 & 0.0 & 0.0 & - \\
$\mathrm{C}_{3}-\mathrm{C}_{4}-\mathrm{C}_{5}-\mathrm{H}_{9}$ & 180.0 & 180.0 & 180.0 & - \\
$\mathrm{H}_{8}-\mathrm{C}_{4}-\mathrm{C}_{5}-\mathrm{C}_{6}$ & 180.0 & 180.0 & 180.0 & - \\
$\mathrm{H}_{8}-\mathrm{C}_{4}-\mathrm{C}_{5}-\mathrm{H}_{9}$ & 0.0 & 0.0 & 0.0 & - \\
$\mathrm{C}_{4}-\mathrm{C}_{5}-\mathrm{C}_{6}-\mathrm{C}_{1}$ & 0.0 & 0.0 & 0.0 & - \\
$\mathrm{C}_{4}-\mathrm{C}_{5}-\mathrm{C}_{6}-\mathrm{H}_{10}$ & 180.0 & 180.0 & 180.0 & - \\
$\mathrm{H}_{9}-\mathrm{C}_{5}-\mathrm{C}_{6}-\mathrm{C}_{1}$ & 180.0 & 180.0 & 180.0 & - \\
$\mathrm{H}_{9}-\mathrm{C}_{5}-\mathrm{C}_{6}-\mathrm{H}_{10}$ & 0.0 & 0.0 & 0.0 & - \\
\hline
\end{tabular}

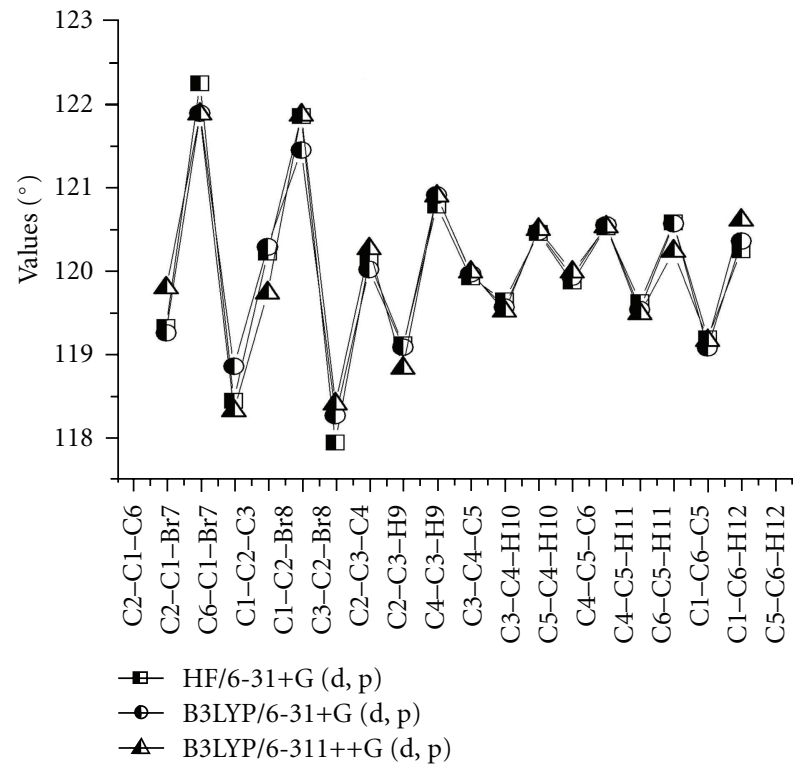

Figure 7: Bond angle differences between theoretical approach (HF and DFT).

it is clear that the $\mathrm{C}-\mathrm{C}$ bond length is compressed exactly in the substitutional place The $\mathrm{C}-\mathrm{Br}$ bond distance cal. $1.908 \AA$ ' by B3LYP/6-311++G (d, p) is just $0.041 \AA$ lower than the reported experimental value of $1.867 \AA$ [14, 15]. The C-Cl bond distance cal. 1.748 $\AA$ by B3LYP/6-311++G $(\mathrm{d}, \mathrm{p})$ is just $0.003 \AA$ greater than the reported experimental value of $1.745 \AA$ [16]. According to the calculated values (B3LYP/6$311++\mathrm{G}(\mathrm{d}, \mathrm{p}))$, the order of the optimized bond angle are as $\mathrm{C}_{1}-\mathrm{C}_{2}-\mathrm{C}_{3}<\mathrm{C}_{2}-\mathrm{C}_{1}-\mathrm{C}_{6}<\mathrm{C}_{3}-\mathrm{C}_{4}-\mathrm{C}_{5}=\mathrm{C}_{4}-\mathrm{C}_{5}-\mathrm{C}_{6}<\mathrm{C}_{1}-$ $\mathrm{C}_{6}-\mathrm{C}_{5}<\mathrm{C}_{2}-\mathrm{C}_{3}-\mathrm{C}_{4}$. The bond angle of $\mathrm{C}_{2}-\mathrm{C}_{1}-\mathrm{Br}_{11}$ is $0.001^{\circ}$ (B3LYP/6-311++G $(\mathrm{d}, \mathrm{p})$ ) larger than the bond angle $\mathrm{C}_{3}-\mathrm{C}_{4}-$ $\mathrm{Cl}_{12}$ since the substitution of chlorine and fluorine atom.

4.2. Vibrational Assignments. The 1-Br-2-CB consists of 12 atoms, and belongs to $C_{S}$ symmetry. Hence the number of

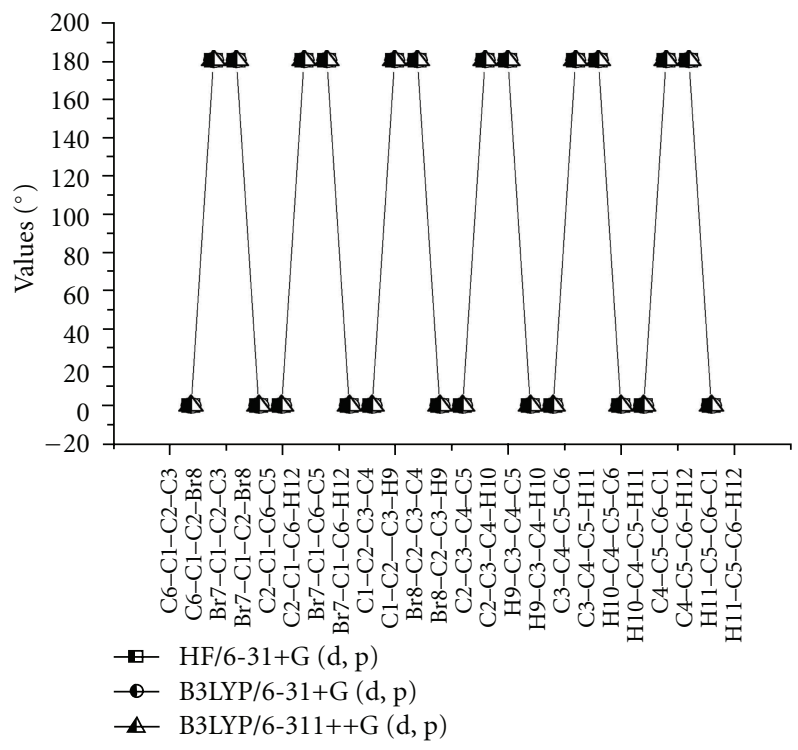

FIGURE 8: Dihedral angle differences between theoretical approach (HF and DFT).

normal modes of vibrations for $1-\mathrm{Br}-2-\mathrm{CB}$ works to 30 . Of the 30 normal modes of vibrations, 21 modes of vibrations are in plane and the remaining 9 are out of plane. The bands that belong to the in-plane modes are represented as $\mathrm{A}^{\prime}$ while the out-of-plane modes as $\mathrm{A}^{\prime \prime}$. Thus the 30 normal modes of vibrations are distributed as $\Gamma_{\mathrm{Vib}}=21 \mathrm{~A}^{\prime}+9 \mathrm{~A}^{\prime \prime}$. All the 30 fundamental vibrations are active both in Raman scattering and in IR absorption. The harmonic-vibrational frequencies calculated for 1-Br-2-CB at HF and DFT-B3LYP levels using the triple split valence basis set along with the diffuse and polarization functions, 6-311G (d, p), observed FT-IR and FT-Raman frequencies for various modes of vibrations are presented in Table 2.

Although basis set are marginally sensitive as observed in the HF and DFT values using 6-31+G+ $(\mathrm{d}, \mathrm{p})$ and $6-311++\mathrm{G}$ $(d, p)$, reduction in the computed harmonic vibrational frequencies are noted. Without affecting the basic level of 


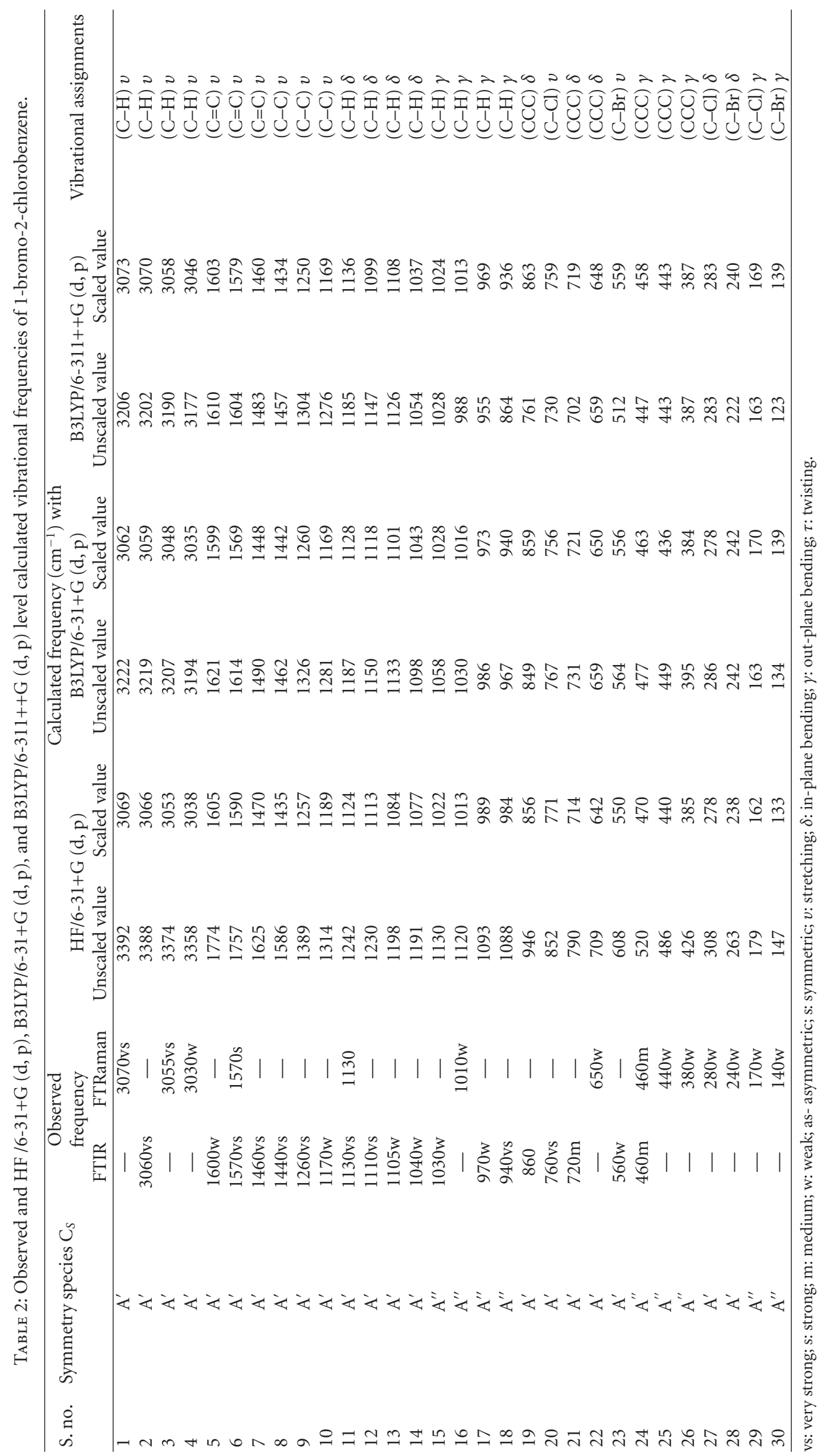




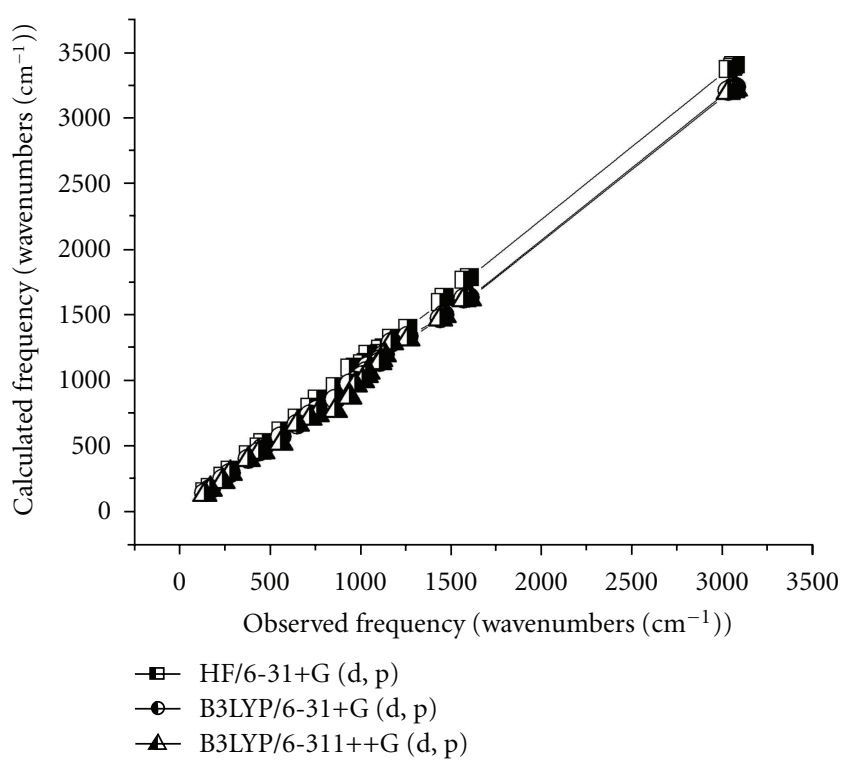

Figure 9: Comparative graph of experimental and calculated frequencies HF and DFT (B3LYP).

calculations, it is customary to scale down the calculated harmonic frequencies in order to get an agreement with the experimental values. The scaled calculated frequencies minimize the root mean square difference between calculated and experimental frequencies for bands with definite identifications.

4.2.1. Computed IR Intensity and Raman Activity Analysis. Computed vibrational spectral IR intensities and Raman activities of the 1-Br-2-CB for corresponding wavenumbers by HF and DFT methods with B3LYP at $6-311 \mathrm{G}++(\mathrm{d}, \mathrm{p})$ basis sets have been collected in Table 3. The title molecule is a nonpolar molecule with $\mathrm{C}_{S}$ point group. Comparison of IR intensity and Raman activity calculated by HF and DFT with B3LYP at 6-311G++ $(\mathrm{d}, \mathrm{p})$ methods with experimental values shows the variation of IR intensities and Raman activities. In the case of IR intensity, the values of HF are found to be higher than B3LYP at $6-31+G(d, P)$ whereas in the case of Raman activity the effect is reversed. The similar effect was also observed in the earlier paper [17]. The comparative plots of IR intensities and Raman activities for four sets are presented in Figures 4 and 5, respectively.

4.2.2. Computed Vibrational Frequency Analysis. The comparative graph of calculated vibrational frequencies by HF and DFT methods at HF/6-31+G (d, p), B3LYP/6-31+G $(d, p)$, and B3LYP/6-311++G (d, p) basis sets for the 1$\mathrm{Br}-2-\mathrm{CB}$ are given in Figure 9. From the figure, it is found that the calculated (unscaled) frequencies by B3LYP with $6-311++G(d, p)$ basis sets are closer to the experimental frequencies than HF method with 6-311G (d, p) basis set. This observation is in line with our earlier work [18]. The standard deviation (SD) calculation made between experimental and computed frequencies (HF/DFT) for the 1- $\mathrm{Br}-2-\mathrm{CB}$ is presented in Table 4. According to the SD, the computed frequency deviation decreases in going from
$\mathrm{HF} / 6-31+\mathrm{G}(\mathrm{d}, \mathrm{p})$ to $\mathrm{B} 3 \mathrm{LYP} / 6-31+\mathrm{G}(\mathrm{d}, \mathrm{p})$ to $\mathrm{B} 3 \mathrm{LYP} / 6-$ $311++\mathrm{G}(\mathrm{d}, \mathrm{p})$. The deviation ratio between $\mathrm{HF} / 6-31+\mathrm{G}(\mathrm{d}$, p) and B3LYP/6-31+G (d, p) is 2.90 and HF/6-311+G (d,p) and B3LYP/6-31+G $(\mathrm{d}, \mathrm{p})$ is 2.88 . It is also observed that the calculated frequencies by B3LYP/6-311++G $(\mathrm{d}, \mathrm{p})$ basis sets are closer to the experimental frequencies than HF method.

4.2.3. $\mathrm{C}-\mathrm{H}$ Vibrations. The aromatic organic compounds structure shows the presence of asymmetric $\mathrm{C}-\mathrm{H}$ stretching vibrations in the region $3100-3000 \mathrm{~cm}^{-1}[19,20]$ which is the characteristics region for recognition on $\mathrm{C}-\mathrm{H}$ stretching vibrations. In the title molecule, four bands have been observed at 3070,3060,3055, and $3030 \mathrm{~cm}^{-1}$ assigned to $\mathrm{C}-\mathrm{H}$ stretching vibrations. Due to the presence of heavy halogen atoms in the benzene ring, the assigned bands are deviated down slightly from the expected range. The $\mathrm{C}-\mathrm{H}$ in-plane and out-of-plane bending vibrations normally take place as a number of strong to weak intensity sharp bends in the region of $1300-1000 \mathrm{~cm}^{-1}$ and $1000-750 \mathrm{~cm}^{-1}$ [21-27], respectively. The bands for $\mathrm{C}-\mathrm{H}$ in-plane bending vibrations are identified at 1130, 1110, 1105, and $1040 \mathrm{~cm}^{-1}$, and the C-H out-of-plane bending vibrations are found at 1030, 1010,970 , and $940 \mathrm{~cm}^{-1}$. Theoretically computed frequencies for $\mathrm{C}-\mathrm{H}$ in-plane and $\mathrm{C}-\mathrm{H}$ out-of-plane bending vibrations by B3LYP/6-31G+ $(\mathrm{d}, \mathrm{p})$ and $6-311++\mathrm{G}(\mathrm{d}, \mathrm{p})$ methods showed excellent agreement with recorded spectrum. Except for some vibrations, all the bending vibrations are in line with the literature. Some of the bending vibrational modes are slightly moved away from the expected region. This is mainly due to the substitutions of halogens with different masses.

4.2.4. $C=C$ Vibrations. Generally the $\mathrm{C}=\mathrm{C}$ stretching vibrations in aromatic compounds are seen in the region of $1430-1650 \mathrm{~cm}^{-1}$. According to Socrates [28], the presence of conjugate substituent such as $\mathrm{C}=\mathrm{C}$ causes a heavy doublet formation around the region $1625-1575 \mathrm{~cm}^{-1}$. The six ring carbon atoms which undergo coupled vibrations which are known as skeletal vibrations give a maximum of four bands in the region $1660-1420 \mathrm{~cm}^{-1}$. As predicted in the earlier references [29], the prominent peaks at 1600, 1570, and $1460 \mathrm{~cm}^{-1}$ are due to strong $\mathrm{C}=\mathrm{C}$ stretching and 1440,1260 , and $1170 \mathrm{~cm}^{-1}$ are due to strong $\mathrm{C}-\mathrm{C}$ skeletal vibrations for the title compound. The peaks at 1600,1570 , and $1460 \mathrm{~cm}^{-1}$ and the peaks at 1440 and $1260 \mathrm{~cm}^{-1}$ are due to quadrant and semicircle stretching of CC bonds, respectively [30]. These four peaks confirm that the compound is aromatic in nature [31]. The peaks are assigned at 860,720 , and $650 \mathrm{~cm}^{-1}$ due to $\mathrm{C}-\mathrm{C}-\mathrm{C}$ in-plane bending vibrations and the peaks at 460 , 440 , and $380 \mathrm{~cm}^{-1}$ are due to C-C-C out-of-plane bending vibrations. Except $\mathrm{C}-\mathrm{C}$ and $\mathrm{CCC}$ vibrations, all the $\mathrm{C}=\mathrm{C}$ stretching vibrations are coherent with the literature data [32]. The $\mathrm{C}-\mathrm{C}$ and $\mathrm{CCC}$ vibrations are pulled considerably to the lower region and are purely due to the substitutions.

4.2.5. $\mathrm{C}-\mathrm{Br}$ Vibrations. The vibration belonging to the bond between the ring and the bromine atom is important as 
TABLE 3: Comparative values of IR intensity and Raman activity between HF/6-31+G (d, p), B3LYP/6-31+G (d, p), and B3LYP/6-311++G (d, p) of 1-bromo-2-chlorobenzene.

\begin{tabular}{|c|c|c|c|c|c|c|c|}
\hline \multirow[t]{2}{*}{ S. no. } & \multirow{2}{*}{$\begin{array}{l}\text { Observed } \\
\text { frequency }\left(\mathrm{cm}^{-1}\right)\end{array}$} & \multicolumn{2}{|c|}{$\begin{array}{l}\text { Calculated with } \\
\mathrm{HF} / 6-31+\mathrm{G}(\mathrm{d}, \mathrm{p})\end{array}$} & \multicolumn{2}{|c|}{$\begin{array}{l}\text { Calculated with } \\
\text { B3LYP/6-31+G }(d, p)\end{array}$} & \multicolumn{2}{|c|}{$\begin{array}{l}\text { Calculated with } \\
\text { B3LYP/6-311++G (d, p) }\end{array}$} \\
\hline & & $\begin{array}{c}\text { IR } \\
\text { intensity (Ai) }\end{array}$ & $\begin{array}{c}\text { Raman } \\
\text { activity (I) }\end{array}$ & $\begin{array}{c}\text { IR } \\
\text { intensity (Ai) }\end{array}$ & $\begin{array}{c}\text { Raman } \\
\text { activity (I) }\end{array}$ & $\begin{array}{c}\text { IR } \\
\text { activity (I) }\end{array}$ & $\begin{array}{c}\text { Raman } \\
\text { intensity (Ai) }\end{array}$ \\
\hline 1 & 3070 & 5.51 & 234.74 & 4.11 & 280.35 & 3.34 & 241.41 \\
\hline 2 & 3060 & 3.84 & 23.15 & 3.04 & 29.11 & 2.55 & 62.85 \\
\hline 3 & 3055 & 8.89 & 104.63 & 7.76 & 121.31 & 6.52 & 114.39 \\
\hline 4 & 3030 & 1.71 & 49.57 & 1.56 & 53.97 & 1.32 & 50.37 \\
\hline 5 & 1600 & 9.54 & 28.55 & 11.09 & 26.93 & 10.37 & 23.82 \\
\hline 6 & 1570 & 4.72 & 10.62 & 4.55 & 11.42 & 4.385 & 11.71 \\
\hline 7 & 1460 & 59.39 & 2.89 & 53.84 & 1.95 & 55.74 & 1.80 \\
\hline 8 & 1440 & 23.59 & 0.07 & 19.83 & 0.08 & 20.07 & 0.06 \\
\hline 9 & 1260 & 5.37 & 0.20 & 0.56 & 9.05 & 0.56 & 9.31 \\
\hline 10 & 1170 & 0.73 & 1.96 & 4.53 & 0.15 & 4.37 & 0.09 \\
\hline 11 & 1130 & 17.33 & 6.72 & 0.04 & 0.54 & 0.07 & 5.27 \\
\hline 12 & 1110 & 12.72 & 5.38 & 3.81 & 2.10 & 3.90 & 2.33 \\
\hline 13 & 1105 & 3.30 & 16.07 & 33.39 & 18.7 & 33.63 & 16.32 \\
\hline 14 & 1040 & 0.02 & 1.08 & 0.03 & 1.32 & 13.09 & 42.11 \\
\hline 15 & 1030 & 12.96 & 36.80 & 12.10 & 42.04 & 41.75 & 2.78 \\
\hline 16 & 1010 & 36.93 & 7.61 & 40.70 & 2.29 & 0.03 & 0.09 \\
\hline 17 & 970 & 1.78 & 0.18 & 0.01 & 0.32 & 1.34 & 0.07 \\
\hline 18 & 940 & 0.32 & 0.70 & 1.36 & 0.27 & 0.00 & 0.04 \\
\hline 19 & 860 & 0.03 & 0.47 & 0.02 & 0.15 & 68.52 & 0.00 \\
\hline 20 & 760 & 84.39 & 0.62 & 66.42 & 0.34 & 21.66 & 1.43 \\
\hline 21 & 720 & 17.54 & 0.79 & 18.95 & 1.43 & 0.33 & 0.49 \\
\hline 22 & 650 & 13.15 & 9.17 & 12.70 & 7.44 & 12.97 & 7.01 \\
\hline 23 & 560 & 0.00 & 0.03 & 0.02 & 0.04 & 0.04 & 0.28 \\
\hline 24 & 460 & 7.97 & 0.02 & 7.32 & 0.04 & 6.08 & 13.53 \\
\hline 25 & 440 & 5.38 & 15.45 & 6.01 & 13.69 & 4.78 & 0.07 \\
\hline 26 & 380 & 0.64 & 4.54 & 0.66 & 3.69 & 0.07 & 4.05 \\
\hline 27 & 280 & 0.48 & 3.24 & 0.66 & 2.50 & 0.74 & 2.65 \\
\hline 28 & 240 & 1.45 & 0.80 & 1.41 & 0.95 & 1.50 & 0.62 \\
\hline 29 & 170 & 0.15 & 1.08 & 0.19 & 1.24 & 0.15 & 1.44 \\
\hline 30 & 140 & 0.04 & 2.19 & 0.04 & 2.59 & 0.08 & 2.24 \\
\hline
\end{tabular}

mixing of vibrations is possible due to the presence of heavy atom $[14,15,33]$. C-Br bond shows lower absorption frequency as compared to $\mathrm{C}-\mathrm{H}$ bond due to the decreased force constant and increase in reduced mass. Bromine compounds absorb strongly in the region $650-485 \mathrm{~cm}^{-1}$ due to the $\mathrm{C}-\mathrm{Br}$ stretching vibrations [34]. Accordingly in the present case, the $\mathrm{C}-\mathrm{Br}$ stretching vibration of the $1-\mathrm{Br}-2-\mathrm{CB}$ is observed at $560 \mathrm{~cm}^{-1}$ in the FT-IR spectrum. The C-Br in-plane bending and out-of-plane bending vibrations are observed at $240 \mathrm{~cm}^{-1}$ and $140 \mathrm{~cm}^{-1}$, respectively. This view is also supported by the above literature.
4.2.6. $\mathrm{C}-\mathrm{Cl}$ Vibrations. The $\mathrm{C}-\mathrm{Cl}$ stretching band is normally expected around $750-580 \mathrm{~cm}^{-1}$ [35]. A strong IR band at $760 \mathrm{~cm}^{-1}$ is assigned to $\mathrm{C}-\mathrm{Cl}$ stretching vibration. The $\mathrm{C}-\mathrm{Cl}$ deformation vibrations are expected around $460-175 \mathrm{~cm}^{-1}$ [34]. A weak Raman band at $280 \mathrm{~cm}^{-1}$ is assigned to the C-Cl in-plane bending vibration; a weak Raman band at $170 \mathrm{~cm}^{-1}$ is assigned to the $\mathrm{C}-\mathrm{Cl}$ out-of-plane bending vibration. When comparison is made with the assignments given in the literature [34-37], the presence of the bromine substituent induced a shift in the $\mathrm{C}-\mathrm{Cl}$ vibrational frequencies to higher values. 
TABLE 4: Standard deviation of frequencies by HF/DFT (B3LYP/) at $6-31+G(d, p)$ and $6-311++G(d, p)$ basis sets.

\begin{tabular}{lccccc}
\hline S. no. & $\begin{array}{c}\text { Basic set } \\
\text { levels }\end{array}$ & $\begin{array}{c}\text { Total } \\
\text { values }\end{array}$ & Average & $\begin{array}{c}\text { Standard } \\
\text { deviation }\end{array}$ & $\begin{array}{c}\text { Deviation } \\
\text { ratio }\end{array}$ \\
\hline & $\begin{array}{c}\text { Experimental } \\
\text { HF/6-311+ } \\
(\mathrm{d}, \mathrm{p})\end{array}$ & 34710 & 1157 & & \\
& 38483 & 1282 & 88.93 & \\
2 & $\begin{array}{c}\text { B3LYP/6-31+ } \\
(\mathrm{d}, \mathrm{p})\end{array}$ & 35961 & 1199 & 30.61 & 2.90 \\
3 & $\begin{array}{c}\text { B3LYP/6-311++ } \\
(\mathrm{d}, \mathrm{p})\end{array}$ & 35288 & 1176 & 30.82 & 2.88 \\
\hline
\end{tabular}

\section{Conclusion}

Complete vibrational analysis has been made in the present work for proper frequency assignments for 1-bromo-2chlorobenzene. The equilibrium geometries have been determined and compared with experimental data. Anharmonic frequencies are determined and analyzed by DFT level of theory utilizing $6-31 \mathrm{G}+(\mathrm{d}, \mathrm{p})$ and $6-311++\mathrm{G}(\mathrm{d}, \mathrm{p})$ basis sets. Good agreement between the calculated and experimental spectra was obtained. The HF/DFT spectra showed better agreement with experimental spectra. However, the difference between the observed and scaled wavenumber values of $\mathrm{C}-\mathrm{C}$ fundamental is very large, because of the presence of the $\mathrm{C}-\mathrm{Cl}$ and $\mathrm{C}-\mathrm{Br}$ bonds. The detailed anharmonic frequencies assignment of 1-B-2-CB, presented in this work, has clarified several ambiguities in the previously reported investigation of the experimental spectra. Computed vibrational analysis showed the standard deviation of computational frequencies.

\section{References}

[1] C. Long, Q. Li, Y. Li, Y. Liu, A. Li, and Q. Zhang, "Adsorption characteristics of benzene-chlorobenzene vapor on hypercrosslinked polystyrene adsorbent and a pilot-scale application study," Chemical Engineering Journal, vol. 160, no. 2, pp. 723-728, 2010.

[2] M. Rossberg et al., "Chlorinated hydrocarbons," in Ullmann's Industrial Chemistry, Wiley-VCH, Weinheim, Germany, 2006.

[3] A. D. Becke, "Density-functional exchange-energy approximation with correct asymptotic behavior," Physical Review A, vol. 38, no. 6, pp. 3098-3100, 1988.

[4] C. Lee, W. Yang, and R. G. Parr, "Development of the ColleSalvetti correlation-energy formula into a functional of the electron density," Physical Review B, vol. 37, no. 2, pp. 785789, 1988.

[5] A. D. Becke, "Density-functional thermochemistry. III. The role of exact exchange," The Journal of Chemical Physics, vol. 98, no. 7, pp. 5648-5652, 1993.

[6] Z. Zhou, D. Du, Y. Xing, and S. U. M. Khan, "Calculation of the energy of activation in the electron transfer reaction not involving the bond rupture the electrode," Journal of Molecular Structure: THEOCHEM, vol. 505, pp. 247-255, 2000.

[7] Y. Carissan and W. Klopper, "Hydrogen abstraction from biphenyl, acenaphthylene, naphthalene and phenanthrene by atomic hydrogen and methyl radical: DFT and G3(MP2)-RAD data," Journal of Molecular Structure: THEOCHEM, vol. 940, no. 1-3, pp. 115-118, 2010.

[8] M. H. Jamróz and J. Cz. Dobrowolski, "Potential energy distribution (PED) analysis of DFT calculated IR spectra of the most stable $\mathrm{Li}, \mathrm{Na}$, and $\mathrm{Cu}(\mathrm{I})$ diformate molecules," Journal of Molecular Structure, vol. 565-566, pp. 475-480, 2001.

[9] D. C. Young, Computational Chemistry: A Practical Guide for Applying Techniques to Real world Problems, John Wiley \& Sons, New York, NY, USA, 2001.

[10] M. Sekerci, Y. Atalay, F. Yakuphanoglu, D. Avci, and A. Başoğlu, "A theoretical study on 1-(thiophen-2-yl-methyl)-2(thiophen-2-yl)-1H-benzimidazole," Spectrochimica Acta Part A, vol. 67, no. 2, pp. 503-508, 2007.

[11] A. P. Scott and L. Radom, "Harmonic vibrational frequencies: An evaluation of Hartree-Fock, Møller-Plesset, quadratic configuration interaction, density functional theory, and semiempirical scale factors," Journal of Physical Chemistry, vol. 100, no. 41, pp. 16502-16513, 1996.

[12] "Gaussian 03 program," Gaussian Inc., Wallingford, Conn, USA, 2000.

[13] M. J. Frisch, A. B. Nielsen, and A. J. Holder, Gauss View Users Manual, Gaussian, Pittsburgh, Pa, USA, 2000.

[14] H. Møllendal, S. Gundersen, M. A. Tafipolsky, and H. Vidar Volden, "The molecular structure of benzene derivatives, part 2: 4-chloro-benzaldehyde by joint analysis of gas electron diffraction, microwave spectroscopy and ab initio molecular orbital calculations," Journal of Molecular Structure, vol. 444, no. 1-3, pp. 47-56, 1998.

[15] S. Samdal, T. G. Strand, M. A. Tafipolsky, L. V. Vilkov, M. V. Popik, and H. V. Volden, "The molecular structure of benzene derivatives part 1.4-fluorobenzaldehyde by joint analysis of gas electron diffraction, microwave spectroscopy and ab initio molecular orbital calculations," Journal of Molecular Structure, vol. 435, no. 1, pp. 89-99, 1997.

[16] A. K. Hermetet, L. J. Ackerman, K. K. Eilts et al., "Structural, spectral and thermal studies of N-2-(4,6-lutidyl)- $N^{\prime}$ chlorophenylthioureas," Journal of Molecular Structure, vol. 605, no. 2-3, pp. 241-247, 2002.

[17] S. Ramalingam, S. Periandy, M. Govindarajan, and S. Mohan, "FTIR and FTRaman spectra, assignments, ab initio HF and DFT analysis of 4-nitrotoluene," Spectrochimica Acta Part A, vol. 75, no. 4, pp. 1308-1314, 2010.

[18] S. Ramalingam, S. Periandy, B. Narayanan, and S. Mohan, "FTIR and FTRaman spectroscopic investigation of 2-bromo4-methylaniline using ab initio HF and DFT calculations," Spectrochimica Acta Part A, vol. 76, no. 1, pp. 84-92, 2010.

[19] L. J. Bellamy, The Infrared Spectra of Complex Molecules, Chapman and Hall, London, UK, 1975.

[20] G. Socrates, Infrared and Raman Characteristics Group Frequencies, Wiley, New York, NY, USA, 3rd edition, 2001.

[21] N. Sundaraganesan, H. Saleem, S. Mohan, M. Ramalingam, and V. Sethuraman, "FTIR, FT-Raman spectra and ab initio DFT vibrational analysis of 2-bromo-4-methyl-phenylamine," Spectrochimica Acta Part A, vol. 62, no. 1-3, pp. 740-751, 2005.

[22] V. Krishnakumar and R. John Xavier, "Normal coordinate analysis of 2-mercapto and 4,6-dihydroxy -2-mercapto pyrimidines," Indian Journal of Pure and Applied Physics, vol. 41, no. 8, pp. 597-601, 2003.

[23] V. Krishnakumar and N. Prabavathi, "Simulation of IR and Raman spectral based on scaled DFT force fields: a case study of 2-amino 4-hydroxy 6-trifluoromethylpyrimidine, with emphasis on band assignment," Spectrochimica Acta Part A, vol. 71, no. 2, pp. 449-457, 2008. 
[24] A. Altun, K. Gölcük, and M. Kumru, "Structure and vibrational spectra of p-methylaniline: Hartree-Fock, MP2 and density functional theory studies," Journal of Molecular Structure: THEOCHEM, vol. 637, pp. 155-169, 2003.

[25] S. J. Singh and S. M. Pandey, Indian Journal of Pure and Applied Physics, vol. 12, pp. 300-304, 1974.

[26] Y. X. Sun, Q. L. Hao, Z. X. Yu, W. J. Jiang, L. D. Lu, and $\mathrm{X}$. Wang, "Experimental and theoretical studies on vibrational spectra of 4-(2-furanylmethyleneamino)antipyrine, 4benzylideneaminoantipyrine and 4-cinnamilideneaminoantipyrine," Spectrochimica Acta Part A, vol. 73, no. 5, pp. 892-901, 2009.

[27] N. Sundaraganesan, B. D. Joshua, and T. Radjakoumar, "Molecular structure and vibrational spectra of 2-chlorobenzoic acid by density functional theory and ab-initio HartreeFock calculations," Indian Journal of Pure and Applied Physics, vol. 47, no. 4, pp. 248-258, 2009.

[28] D. N. Sathyanarayana, Vibrational Spectroscopy Theory and Application, New Age International, New Delhi, India, 2004.

[29] V. R. Dani, Organic Spectroscopy, Tata-MacGraw Hill Publishing, New Delhi, India, 1995.

[30] J. Mohan, Organic Spectroscopy-Principle and Applications, Narosa Publishing House, New Delhi, India, 2nd edition, 2005.

[31] P. S. Kalsi, Spectroscopy of Organic Compounds, Wiley Eastern, New Delhi, India, 1993.

[32] A. R. Prabakaran and S. Mohan, Indian Journal of Physics, vol. 63B, pp. 468-473, 1989.

[33] N. S. Chiu, J. D. Ewbank, M. Askari, and L. Schäfer, "Molecular orbital constrained gas electron diffraction studies. Part I. Internal rotation in 3-chlorobenzaldehyde," Journal of Molecular Structure, vol. 54, pp. 185-195, 1979.

[34] E. F. Mooney, "The infra-red spectra of chloro- and bromobenzene derivatives-II. Nitrobenzenes," Spectrochimica Acta, vol. 20, no. 6, pp. 1021-1032, 1964.

[35] C. S. Hiremath and T. Sundius, "Vibrational spectra, ab initio/ DFT electronic structure calculations, and normal coordinate analysis of 2-bromo-5-fluorobenzaldehyde," Spectrochimica Acta Part A, vol. 74, no. 5, pp. 1260-1267, 2009.

[36] L. J. Bellamy, The Infrared Spectra of Complex Molecules, Chapman \& Hall, London, UK, 1975.

[37] G. Varsanyi, Assignments for Vibrational Spectra of 700 Benzene Derivatives, vol. 1, Hilger, London, UK, 1974. 

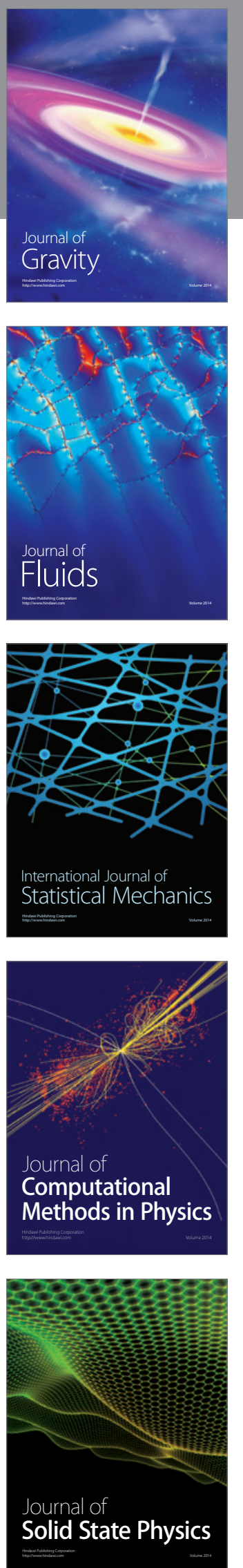

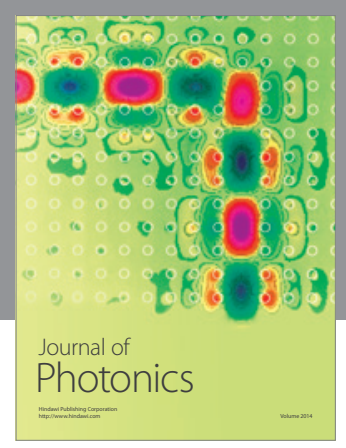

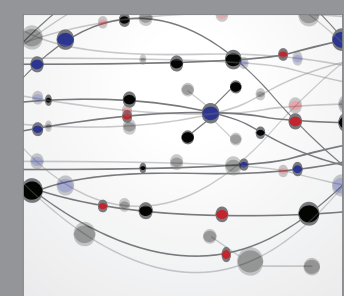

The Scientific World Journal
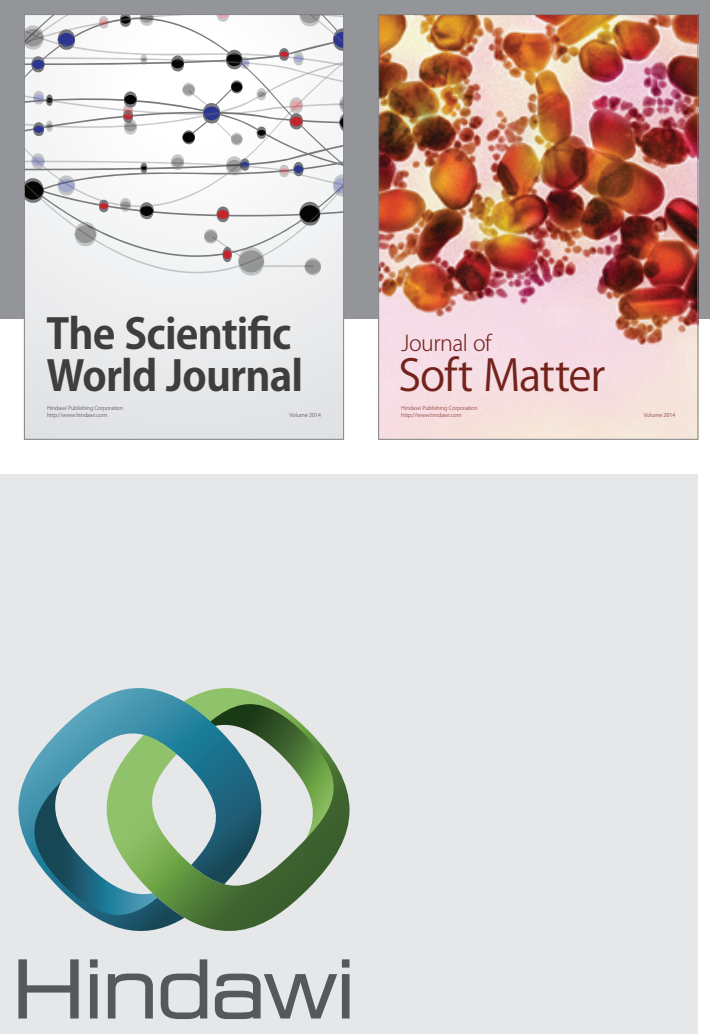

Submit your manuscripts at

http://www.hindawi.com
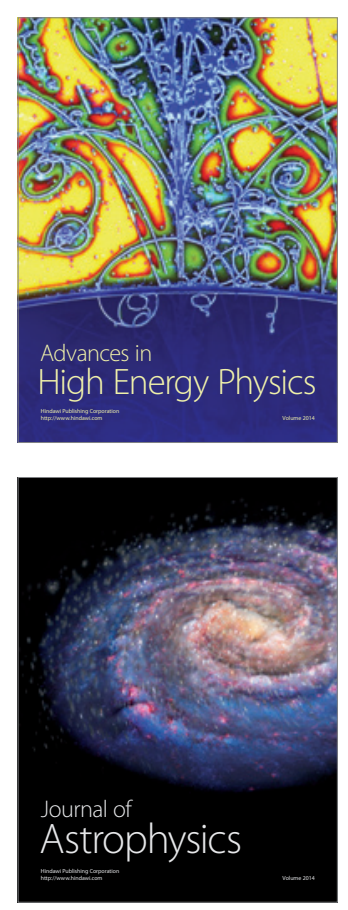
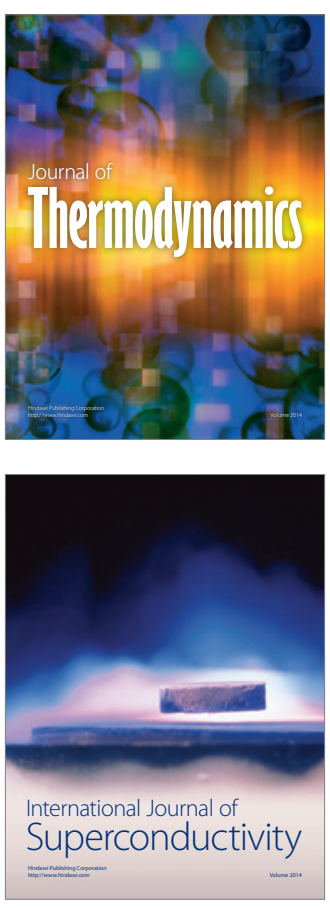
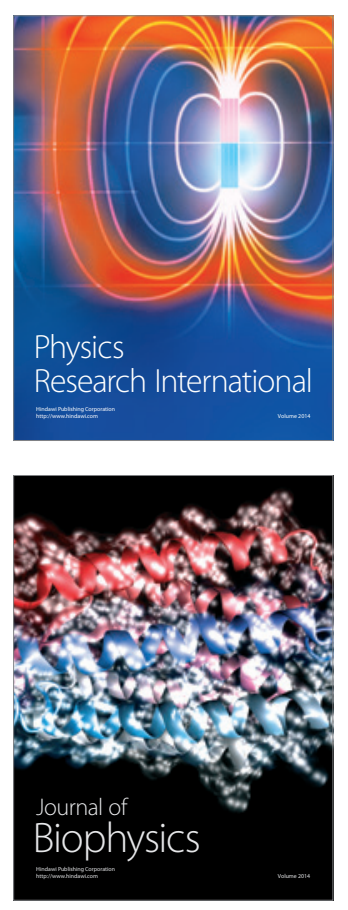
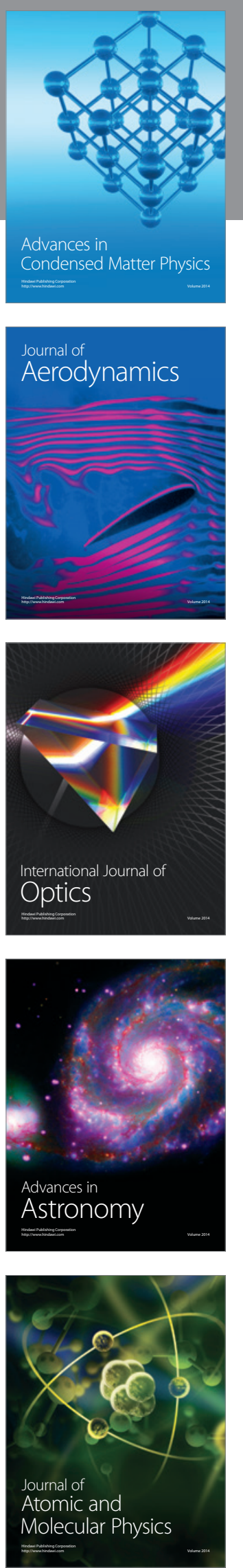